\title{
A Prospective Cohort Study Analysing Maternal \& Foetal Outcome of Epidural Analgesia in Primiparous- A Boon or Bane!
}

\author{
Surendra ${ }^{1}$ and Vinu Choudhary ${ }^{2 *}$ \\ ${ }^{1}$ Department of Obstetrics and Gynaecology, SP Medical College, India \\ ${ }^{2}$ Department of Obstetrics and Gynaecology, SMS Medical College, India
}

Submission: July 30, 2018; Published: August 24, 2018

*Corresponding author: Vinu Choudhary, Department of Obstetrics \& Gynaecology, SMS Medical College, Jaipur, Rajasthan, India, Tel: 9116386239; Email: vinuc16@gmail.com

\begin{abstract}
Introduction: Childbirth is a multidimensional experience and when considering treatment, one must balance between pain relief and other aspects, such as physical, emotional, psychological, sociologic, and sometimes religious considerations. In other words, pain relief may not be enough to make childbirth a fulfilling and satisfactory experience. In this section we will consider the goals of therapy for labor pain and how neuraxial analgesia helps to accomplish these goals. The aim of the study was to evaluate the effect of epidural analgesia on duration of labor, maternal and foetal outcome.
\end{abstract}

Methodology: The present study was a prospective cohort study conducted in a tertiary care hospital in Dept. of obstetrics \& gynaecology. Registration of patients was from August 2016 to July 2017. The women in labor who have fulfilled inclusion criteria are enrolled in the study. They were counselled when they were admitted in labor room, during 1st stage of labor. Detailed history was taken according to the proforma. General physical examination done. Systemic examination including per cephalopelvic disproportion. The primary outcome was duration of labor (first and second stage of labor). Secondary outcome measures were the incidence of vaginal delivery, caesarean sections and instrumental vaginal delivery. Neonatal outcome in form of APGAR score at 5 min noted.

Result: Both the groups were matched with respect to characters like maternal age, height, weight, gestational age. Total number of patients in this study were 40 . Majority of patients were between 20-26 years with mean age of 23.45 years \& 24.45 yrs in epidural \& control Gp. respectively. Results of present study demonstrated that epidural analgesia provides excellent pain relief. There was statistically significant difference in mean duration of first stage of labor in both groups with $\mathrm{p}$ value of $<0.05$ which is statistically significant. In regard of mode of delivery there was no Statistically significant difference observed in both groups. Perception of pain in EA group was very low with $100 \%$ of patients giving good VAS score. Patients acceptability in EA group was $100 \%$ all of them were interested to take epidural analgesia in next labor.

Conclusion: Epidural analgesia is commonly performed to relieve labor pain. Compared with other techniques, it is the most effective form of analgesia. Recent innovations in drug combinations and delivery systems have resulted in a flexible technique that meets the needs of most parturients in a safe and effective manner.

Keywords: Epidural analgesia; Labor pain; Pain perception; I Stage of labor; II Stage of labor; APGAR Score; VAS Scale

\section{Introduction}

Labor is a highly complex event. Labor may be the most painful experience many women ever encounter. The experience is different for each woman and the different methods chosen to relieve pain depend upon the techniques available locally and the personal choice of the individual. Pain relief in labor has always been surrounded with myths and controversies. Hence, providing effective and safe analgesia during labor has remained an ongoing challenge [1,2] (Table 1). Epidural analgesia refers to local anaesthetics and adjuvants injected into the epidural space. Spinal anaesthesia refers to local anaesthetic, with or without adjuvants, injected into the subarachnoid space. Combined spinal-epidural analgesia includes analgesia initiated with an intrathecal injection and placement of an epidural catheter to provide a route for additional drug [3] (Table 2). Neuraxial analgesia includes spinal, epidural, and combined spinal-epidural analgesia. More recently, combined spinal-epidural analgesia has become popular. The spinal component provides rapid analgesia with very little motor block of the lower extremities. An epidural catheter is then placed to ensure analgesia is available throughout labor [2,3] (Figure 1). Effective pain relief has become an important part of obstetric medicine (Table 3). 
Table 1: Demographic profile of patients.

\begin{tabular}{|c|c|c|}
\hline Characteristics & Epidural group & Control group \\
\hline Mean age (yrs) & 23.45 & 24.45 \\
\hline Mean Birth weight (Kg) & 68.33 & 69.91 \\
\hline Mean height (cm) & 156.2 & 154.4 \\
\hline Mean gestational age(wks) & 38.6 & 38.9 \\
\hline
\end{tabular}

Table 2: Mean Duration of different stages of labour in both groups.

\begin{tabular}{|c|c|c|c|}
\hline Group & Stage I (min.) & Stage II (min.) & Stage III (min.) \\
\hline Gp. A (Mean Dur.) & $190 \mathrm{~min}$. & $36 \mathrm{~min}$ & $8 \mathrm{~min}$ \\
\hline Gp. B (Mean Dur.) & $251 \mathrm{~min}$ & $27 \mathrm{~min}$ & $7 \mathrm{~min}$ \\
\hline P value & $<0.05$ & $<0.05$ & $>0.05$ \\
\hline
\end{tabular}

Table 3: Distribution of cases with regards to mode of delivery.

\begin{tabular}{|c|c|c|}
\hline Mode of delivery & Gp A (N= 20) & Gp.B (N=20) \\
\hline Normal Vaginal & 14 & 16 \\
\hline Assisted Vaginal & 4 & 2 \\
\hline Caesarean section & 2 & 2 \\
\hline
\end{tabular}

\section{Demographic features of both groups}

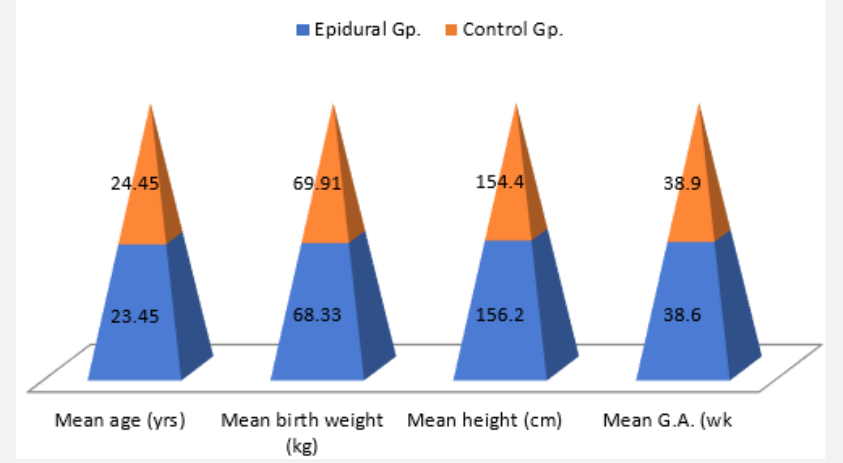

Figure 1: Demographic profile of patients.

The history of modern analgesia during childbirth can be traced back to 1847 with the application of ether and, later, chloroform. Pain impulses from the cervix and lower uterine segment during the first stage of labor are transmitted via the visceral afferent nerve fibres to the spinal cord at the level of T10-L1. Pain during the expulsion stage is mainly somatic, transmitted via the pudendal nerves to spinal segments S2-S4 [2-4] (Figure 2). Psychological factors which can influence the perception of pain during childbirth include anxiety sensitivity, the presence of a trusted person, cultural factors and preparedness through, for instance, prenatal classes. Stress and pain during labor have been known to cause increased blood pressure, cardiac output and catecholamine concentrations in the plasma. The latter in turn reduces uterine perfusion. Epinephrine is known for its tocolytic effect in this case. Changes in the uteroplacental blood flow are normally tolerated well by healthy foetuses. However, in the case of a pre-existing uteroplacental insufficiency, for instance preeclampsia, intrauterine growth retardation or diabetes mellitus may present a risk for the foetus. A traumatic, excessively painful childbirth may cause serious mental health disorders, possibly resulting in post-natal depression or even post-traumatic stress disorder, as well as causing difficulties related to sexuality and mother-child bonding.

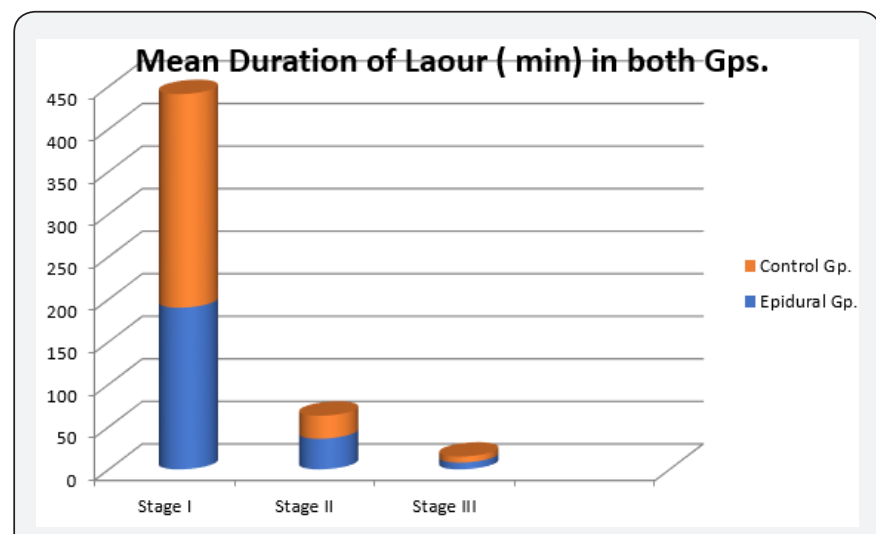

Figure 2: Mean Duration of different stages of labor in both groups.

\section{Properties of ideal labor analgesia}

1. Effective pain relief

2. Safe

3. Minimal effects on progress or outcome of labor

4. Minimal effects on the foetus or new-born

5. Minimal maternal side effects

a. Lower limb motor block

b. Pruritus

c. Nausea

The aim of the study was to evaluate the effect of epidural analgesia on duration of labor, maternal and foetal outcome.

\section{Methodology}

The present study was a prospective cohort study conducted in a tertiary care hospital in Dept. of obstetrics \& gynaecology at SMS Medical College. Registration of patients was from August 2016 to July 2017. They were registered when admitted under Obstetrics and Gynaecology Department. At the time of registration, the patients with exclusion criteria were not enrolled for study.

\section{Inclusion criteria}

a. All patients with full term pregnancy (37-42 weeks)

b. Those who have entered spontaneous labor with vertex presentation

c. Those without any previous uterine surgery

d. Clinically adequate pelvis, cephalopelvic disproportion ruled out. 


\section{Exclusion criteria}

a. Pregnancy with medical disorder (heart disease, diabetes mellitus)

b. Preeclampsia

c. Eclampsia

d. Previous LSCS.

The data is collected in predesigned proforma. The variables are duration of labor, mode of delivery, APGAR score of new born at 1 minute and 5 minutes, pain perceived by the subject. This study design was developed in association with anaesthetist and approved by the local ethical committee. Study patients were allocated in two groups:

a. Group A The women in early labor who desired epidural analgesia (study group EA).

b. Group B The women in labor who were not willing for labor analgesia (control group NA).

The women in labor who have fulfilled inclusion criteria are enrolled in the study. They were counselled when they were admitted in labor room, during 1st stage of labor. Detailed history was taken according to the proforma. General physical examination done. Systemic examination including per cephalopelvic disproportion (Figure 3).

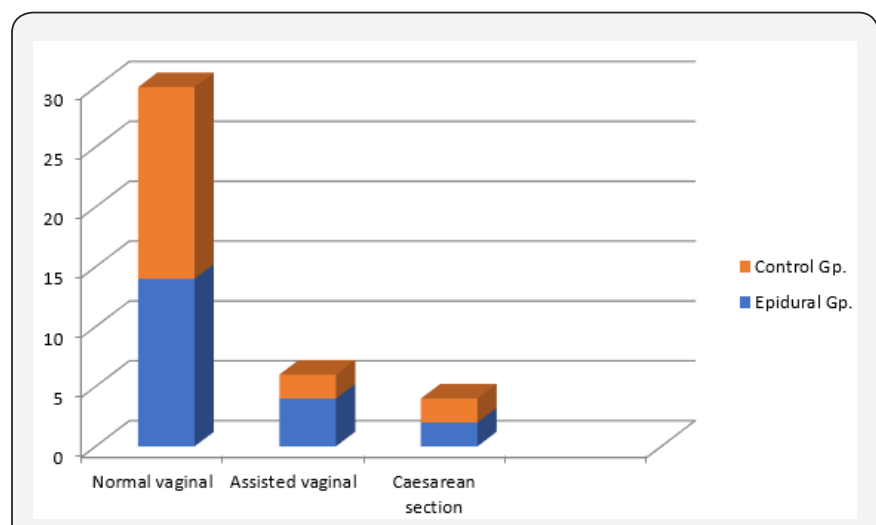

Figure 3: Distribution of cases with regards to mode of delivery.

Table 4: Distribution of the cases according to APGAR 1 minute and 5 minutes.

\begin{tabular}{|c|c|c|}
\hline Group & APGAR score at 1 min & APGAR score at 5 min \\
\hline Gp. A (Mean) & 7.8 & 8.9 \\
\hline Gp. B (Mean) & 7.7 & 9.0 \\
\hline P value & P value $>0.05$ & $>0.05$ \\
\hline
\end{tabular}

Maternal heart rate, blood pressure and level of block were monitored every 5 minutes for first 15 minutes following insertion, then every half hour throughout the procedure. Top up was given as per requirement i.e. as mother starts having pain sensation (Table 4). Top up dose was $10 \mathrm{ml}$ bolus of $0.1 \%$ bupivacaine +2 $\mathrm{mcg} / \mathrm{ml}$ fentanyl on demand was given by anaesthesiologist after strict hand wash and alcohol rub. Prior to each top up - foetal heart rate, level of block, maternal pulse and blood pressure were assessed. VAS i.e. visual analogue scale is a unidimensional measure of pain intensity (Figure 4). It comprises of horizontal line or vertical line usually $100 \mathrm{~mm}(10 \mathrm{~cm})$, anchored by 2 verbal descriptors, one for each symptom extreme. Patient was asked to place a finger over the scale, according to the intensity of pain felt by her. Using a ruler, the score is determined by distance $(\mathrm{mm})$ on $10 \mathrm{~cm}$ line between no pain and patients mark providing a range of scores $0-100 \mathrm{~mm}[4,5]$ (Table 5). The primary outcome was duration of labor (first and second stage of labor). Secondary outcome measures were the incidence of vaginal delivery, caesarean sections and instrumental vaginal delivery. Neonatal outcome in form of APGAR score at 5 min noted.

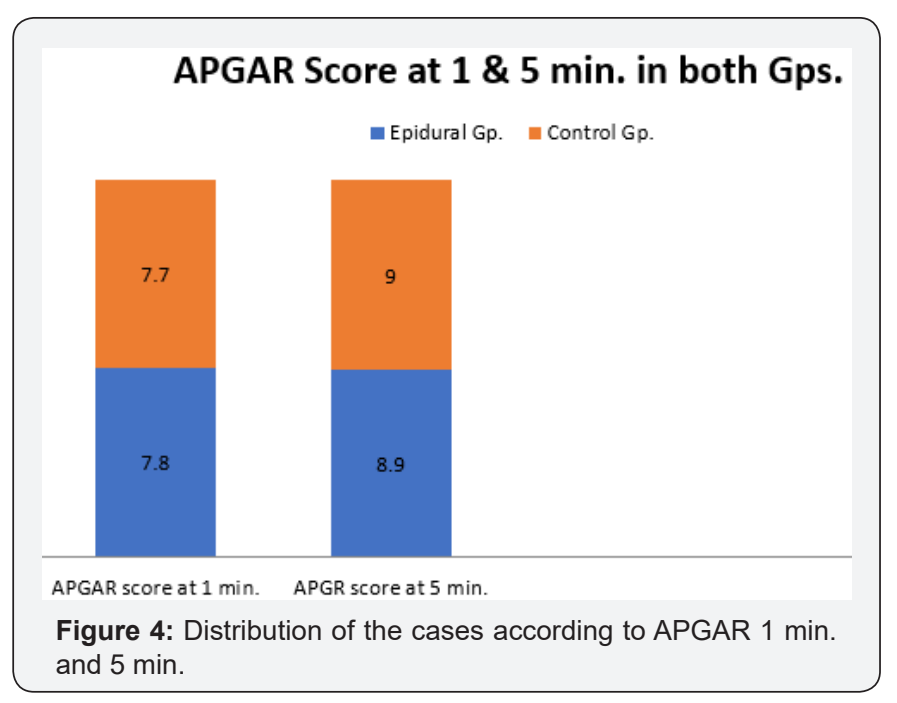

Table 5: Efficacy of Analgesia in both groups.

\begin{tabular}{|c|c|c|c|}
\hline VAS Score & Epidural Gp. & Control Gp. & P value \\
\hline No pain (0-4) & 16 & 0 & $<0.05$ \\
\hline Mild pain (5-44) & 03 & 2 & $>0.05$ \\
\hline Moderate Pain (45- 74) & 01 & 4 & $>0.05$ \\
\hline Severe pain (75-100) & 0 & 14 & $>0.05$ \\
\hline
\end{tabular}

\section{Results}

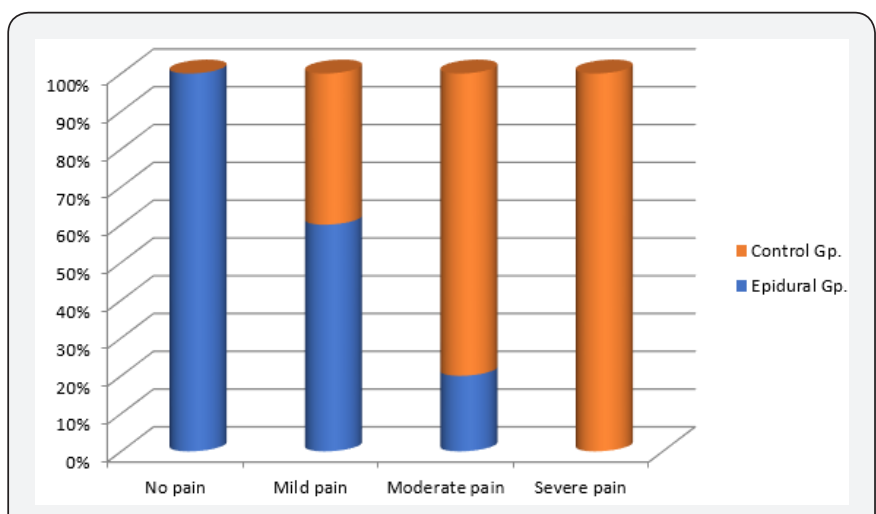

Figure 5: Efficacy of Analgesia in both groups.

Statistical analysis was performed with the SPSS, version 20 for Windows statistical software package (SPSS inc., Chicago, il, 
USA). The Categorical data were presented as numbers (percent) and were compared among groups using Chi square test. Groups were compared for demographic data were presented as mean and standard deviation and were compared using by students t-test. PP value $<=0.05$ is considered statistically significant [6] (Figure 5).

\section{Discussion}

Both the groups were matched with respect to characters like maternal age, height, weight, gestational age. Total number of patients in this study were 40 . Majority of patients were between 20-26 years with mean age of 23.45 years \& 24.45 yrs in epidural \& control Gp. respectively. Results of present study demonstrated that epidural analgesia provides excellent pain relief than no analgesia similar to a study by Anim S et al. [7]. To provide effective analgesia fentanyl was added which further reduced the amount of bupivacaine needed during labor. We instituted epidural analgesia only after confirming that patient has entered active stage of labor.

There was statistically significant difference in mean duration of first stage of labor in both groups with $p$ value of $<0.05$ which is statistically significant, as opposed to study by Wong FM et al. [3] \& Vasudha et al. [8]. Second stage of labor was slightly prolonged in Epidural gp. (Gp. A) \& Control Gp. (Gp. B) supported by Vasudha et al. [8] \& Agarwal D et al. [4]. In current study, the second stage was found to be prolonged in epidural group as compared to control. Short duration of first stage may be because of better analgesia with epidural resulting to decrease inhibitory effect of catecholamines on uterine contractility hence faster cervical dilatation.

In our study mode of delivery was either vaginal, instrumental or caesarean section in both groups. With regard to mode of delivery there was no Statistically significant difference observed in both groups, $\mathrm{p}$ values not significant, our study results are in agreement with several previous studies by Agarwal D et al. [4], Mousa et al. [5] \& Sienko et al. [6]. Present study showed no difference in APGAR scores in both groups similar to studies by Agrawal R et al. [4] \& Mousa et al. [5]. Few early studies have reported significantly higher incidences of caesarean or instrument deliveries with epidural analgesia as compared with systemic opiate drugs.

Perception of pain in EA group was very low with $100 \%$ of patients giving good VAS score. Patients acceptability in EA group was $100 \%$ all of them were interested to take epidural analgesia in next labor if they desire to become pregnant again. In non-epidural group only $54 \%$ patients tolerated pain very well and were happy without any analgesia, but $46 \%$ patients had experience of severe pain, so they were willing to take epidural analgesia in next pregnancy if desired.

\section{Conclusion}

Childbirth is a multidimensional experience and when considering treatment, one must balance between pain relief and other aspects, such as physical, emotional, psychological, sociologic, and sometimes religious considerations. In other words, pain relief may not be enough to make childbirth a fulfilling and satisfactory experience. In this section we will consider the goals of therapy for labor pain and how neuraxial analgesia helps to accomplish these goals $[9,10]$. Experiencing labor pains and giving birth to infant is normal physiological process. Though it is a natural phenomenon, it produces severe pain which requires analgesia to relieve pain during labor. Many of the women prefer caesarean section as they cannot tolerate labor pains. With the use of epidural analgesia, we can definitely reduce the rate of caesarean section and prevent the women from undergoing unnecessary caesarean section.

\section{Key message}

Neuraxial analgesia is commonly performed to relieve labor pain. Compared with other techniques, it is the most effective form of analgesia. Recent innovations in drug combinations and delivery systems have resulted in a flexible technique that meets the needs of most parturients in a safe and effective manner.

\section{References}

1. Lang A J, Sorrell J T, Rodgers C S (2006) Anxiety sensitivity as a predictor of labor pain. Eur J Pain 10(3): 263-270.

2. Caton D Philadelphia (2009) The History of obstetric Anesthesia. Elsevier Mosby pp. 3-13.

3. Wong CA (2009) Advances in labor analgesia. Int J Women's Health 1: 139-154.

4. Agrawal D, Makhija B, Arora M, Haritwal A, Gurha P (2014) The effect of epidural analgesia on labour, mode of delivery and neonatal outcome in nullipara of India, 2011-2014. J Clin Diag Res 8(10): OC03.

5. Mousa WF, Al Metwalli R, Mostafa M (2012) Epidural analgesia during labor vs no analgesia: a comparative study. Saudi J Anaesthesia 6(1): 36-40.

6. Sienko J, Czajkowski K, Swiatek zdzienicka M (2005) Epidural analgesia and the course of delivery in term primiparas. Ginekol Pol 76(10): 806811.

7. Anim Somuah M, Smyth RM, Jones L (2011) Epidural versus nonepidural or no analgesia in labour. Cochrane Database Syst Rev: CD000331.

8. Sawant V, Kumbhar A (2018) Labour with low dose epidural analgesia: maternal perception and fetal outcome. Int J Reprod Contracept Obstet Gynecol 7: 689-693.

9. Thomas EJ Healy, Paul R Knight (2004) Obstetric anaesthesia, Wylie and Churchill Davidsons, A practice of anaesthesia, $7^{\text {th }}$ Edition.

10. Crawford JS (1972) Lumbar Epidural block in Labour, a clinical analysis. Br J Anesth 44(1): 66-74. 
Your next submission with Juniper Publishers will reach you the below assets

- Quality Editorial service

- Swift Peer Review

- Reprints availability

- E-prints Service

- Manuscript Podcast for convenient understanding

- Global attainment for your research

- Manuscript accessibility in different formats ( Pdf, E-pub, Full Text, Audio)

- Unceasing customer service

Track the below URL for one-step submission https://juniperpublishers.com/online-submission.php 